\title{
High-throughput Screening of Surface Displayed Gene Products
}

\author{
Gerald Walter ${ }^{1 *}$, Zoltan Konthur and Hans Lehrach \\ ${ }^{1}$ Biorchard AS, Nedre Skogvei 14, N-0281 Oslo, Norway \\ Max Planck Institute of Molecular Genetics, Ihnestrasse 73, D-14195 Berlin, Germany
}

\begin{abstract}
With the human genome project approaching completion, there is a growing interest in functional analysis of gene products. The characterization of large numbers of proteins, their expression patterns and in vivo localisations, demands the use of automated technology that maintains a logistic link to the encoding genes. As a complementary approach, phage display is used for recombinant protein expression and the selection of interacting (binding) molecules. Cloning of libraries in filamentous bacteriophage or phagemid vectors provides a physical link between the expressed protein and its encoding DNA sequence. High-throughput technology for automated library handling and phage display selection has been developed using picking-spotting robots and a module for pin-based magnetic particle handling. This system enables simultaneous interaction screening of libraries and the selection of binders to different target molecules at high throughput. Target molecules are either displayed on high-density filter membranes (protein filters) or tag-bound to magnetic particles and can be handled as native ligands. Binding activity is confirmed by magnetic particle ELISA in the microtitre format. The whole procedure from immobilisation of target molecules to confirmed clones of binders is automatable. Using this technology, we have selected human $\mathrm{scFv}$ antibody fragments against expression products of human cDNA libraries.
\end{abstract}

\section{INTRODUCTION}

Drug discovery is traditionally based on the screening for desired pharmacological activities of large numbers of different molecules. The diversity of these molecules is usually created by combinatorial chemistry, and the number of random permutations is enormous. Very large molecular libraries must be screened, and the success rate is low. In contrast, the genomic approach to drug discovery starts from the limited diversity of molecules encoded in the genomes of human and other organisms. Assuming that these molecules went through long periods of evolution and play important roles in cells and tissues, they are privileged candidates for pharmacologically active compounds or drug targets. Numerous international genome initiatives are currently creating large amounts of DNA sequence data on the human and other genomes. This structural information is the blueprint for all functions of an organism, and many phenotypes can already be

\footnotetext{
*Address correspondence to this author at Biochard AS, Nedre Skogvei 14, N-0281 Oslo, Norway, Telephone +47 2252 4692, e-mail gerald@biorchard.com
}

pinpointed to their genetic origin in a DNA (gene) sequence. We are now approaching a new phase of genome research, called proteomics, in which we will elucidate the processes that turn sequence information into function. The main molecular players in this phase are the proteins, diverse molecules built from 20 different building blocks (amino acids) whose sequences are encoded in the DNA (gene) sequences, thus creating a great deal of diversity in the proteins three-dimensional structures. This diversity enables complex networks of interacting molecules in cells and tissues, which are instrumental for the functioning of an organism. Knowledge about these interactions and their active molecules is of paramount importance for the understanding of human body functions. The medicinal application of this knowledge will lead to new generations of drugs for the diagnostics and therapeutics markets.

The development of such drugs will be based on the identification of interacting molecules (e.g. proteins) and the gene (DNA) sequences encoding them. This protein-DNA link can either be logistic or physical or a combination of both. The complex 


\section{High-throughput gene expression and interaction screening}

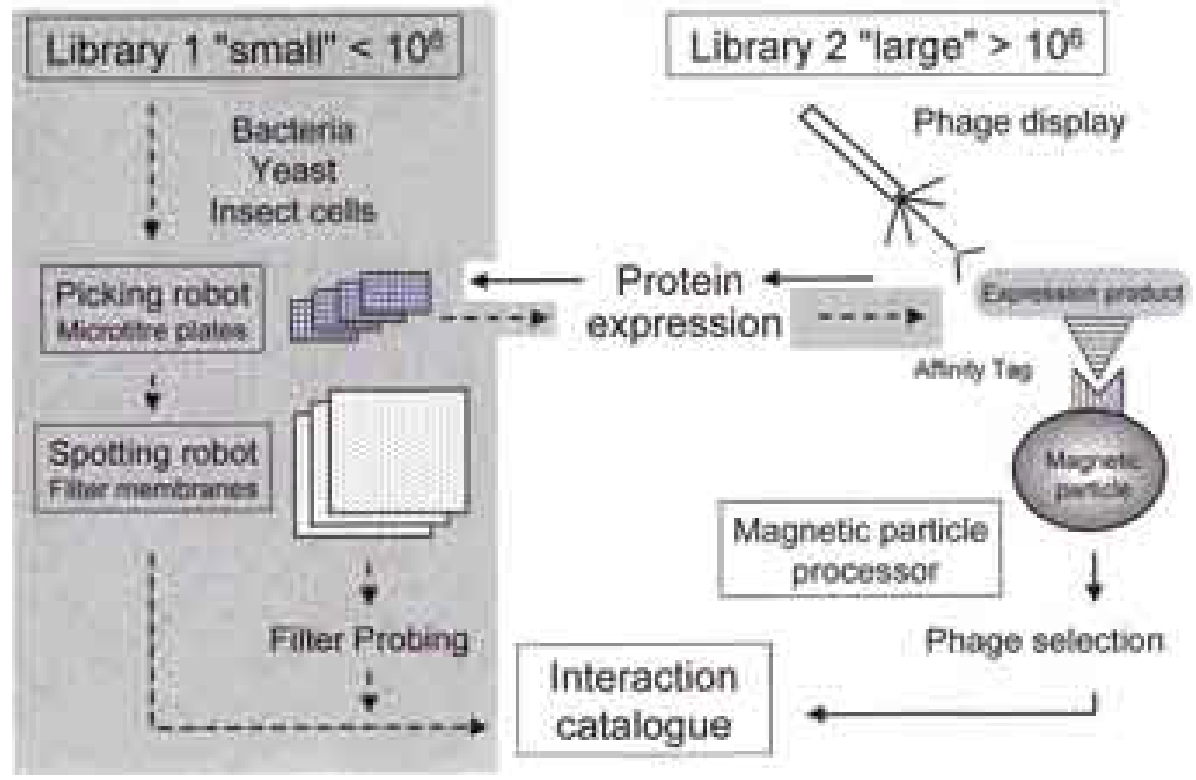

Fig. (1). High-throughput technology for gene expression and interaction screening enables the creation of interaction catalogues, due to a high degree of parallelisation, including logistic and physical links between gene products and their encoding (DNA) sequence information. Left, robot technology, allowing the automated handling of arrayed molecular libraries in the order of up to $10^{6}$ individual species or clones ("library 1"). Right, phage display, providing a physical gene productDNA link and allowing the handling of even larger libraries (e.g. $10^{9}$ different clones, "library 2").

nature of molecular interactions and the large numbers of diverse molecules require highthroughput technology, allowing a sufficient degree of parallelisation Fig. (1). The logistic proteinDNA link is provided by robot technology, enabling the parallel handling of molecular libraries in the order of up to $10^{6}$ individual species or clones ("library 1"). As a complementary approach, phage display provides a physical link and allows the handling of even larger libraries (e.g. $10^{9}$ different clones, "library 2"). Typically, a single filamentous bacteriophage of "library 2 " displays a specific protein molecule (e.g. antibody) on its surface which is able to bind to an interacting partner molecule of "library 1" (e.g. antigen). In this way, specific molecular partners can be selected by fishing phage particles.

Here, we review the combination of different modules of high-throughput technology and library resources and their use in functional genomic analysis.

\section{AUTOMATED HANDLING \\ (ROBOTIC) LIBRARY}

Robot technology for automated library handling in genomics was developed at the
Department Lehrach (MPI-MG Berlin, Germany, formerly ICRF London, U.K.) in the early 1990's [1-3]. This technology is mainly based on linear drives (inductive motors with magnets and coils), enabling fast and precise movements of robotic arms in three dimensions. Similar machines are now available commercially from KBiosystems Limited (Basildon, Essex, U.K.) and Genetix (New Milton, Hampshire, U.K.). The robots are modular and can be used for picking, re-arraying and spotting of libraries.

\section{ROBOT PICKING}

Library-transformed bacteria are evenly plated onto square (245 mm x $245 \mathrm{~mm}$ ) agar plates (e.g. NUNC Bio Assay Dish) and grown at $37^{\circ} \mathrm{C}$ overnight. A CCD camera mounted onto the picking robot scans the plate, and the software classifies and selects well-separated colonies. Those colonies are individually picked with a 96pin picking head and collectively transferred into media-filled 384-well microtitre plates at a speed of approx. 3,000 colonies/h. Colonies are grown in the microtitre wells at $37^{\circ} \mathrm{C}$ overnight. The original library is replicated to produce master and working copies by inoculating colonies into new media- 
filled 384-well plates. Libraries are stored in glycerol-containing media at $-70^{\circ} \mathrm{C}$.

\section{ROBOT REARRAYING}

After initial testing, libraries can be rearrayed by using the picking-spotting robot to re-group selected clones, e.g. protein expressing clones. Clones with user-defined coordinates are individually taken from 'precursor' plates and inoculated into 'new' plates, laid out in the bed of the robot. The machine takes the required 'precursor' plate and uses the standard picking head to collect individual clones, automatically changing precursor plates. Once all 96 pins of the picking head have been loaded with bacteria, the complete picking head inoculates a quadrant of a new plate.

\section{ROBOT SPOTTING}

Working copies of libraries are spotted (gridded, arrayed) in parallel onto Nylon (e.g. Hybond $\mathrm{N}+$, Amersham; for DNA analysis) or PVDF (e.g. Immobilon P, Millipore; for protein analysis) filter membranes (222 $\mathrm{mm} \times 222 \mathrm{~mm}$, twelve to fifteen membranes per run) at a speed of over 100,000 samples/h using the robot's 384-pin spotting head. High-density spotting patterns (50-500 nl per spot) can be produced with upper limits of $8 \times 8$ $(147,456$ spots per filter) for DNA and $5 \times 5$ (27,648 spots per filter) for protein analysis. Clones are usually spotted in duplicate for confirmation of specific hybridisation signals. High-density filters are placed onto square (245 $\mathrm{mm} \times 245 \mathrm{~mm}$ ) agar plates (e.g. NUNC Bio Assay Dish) and bacterial colonies are grown at $37^{\circ} \mathrm{C}$ for DNA and at $30^{\circ} \mathrm{C}$ for protein analysis.

\section{HIGH-DENSITY IMAGE CAPTURE AND ANALYSIS}

Images of probing signals from arrayed clones are scanned by a CCD camera. Scanned images are displayed on a computer screen, and positive clones are identified either manually or by image analysis software (e.g. Visual Grid, GPC, Martinsried, Germany) assigning clone names (coordinates in microtitre plates) to signal intensities. Positive clones are defined by a minimal signal intensity threshold.

\section{HIGH-DENSITY GENE IDENTIFICATION}

Specific genes are identified in the libraries in a high-density format by either hybridisation with gene-specific probes or "Oligonucleotide Fingerprinting". Alternatively, tag sequencing or mass spectrometry of peptide fragments is used for gene identification. For gene-specific probing, libraries spotted onto Nylon (DNA filters, Fig. (2) are hybridised with cDNA clones, characterised earlier by tag sequencing and homology search against the nucleotide databases (GenBank, EMBL). For example, libraries of clones sequenced in the EST project of Washington University/Merck are obtained through the IMAGE-consortium. For a fraction of those clones, a function can be deduced from homology to database entries. Technically, the polymerase chain reaction (PCR) is used for labeling cDNA clones either radioactively by random priming or non-radioactively by incorporation of DIG-dUTP. For oligonucleotide fingerprinting, inserts from cDNA clones are amplified in the PCR robot. PCR products are spotted onto Nylon membranes using the spotting robot. Theoretical analysis and preliminary computer simulations indicate that about 100-200 sequence-specific hybridisations of labeled octanucleotides to about 100,000 PCR products of $1-1.5 \mathrm{~kb}$ length will generate sufficient information for classifying these clones into groups of identical or related genes [1,4] and to identify the genes by homology search against the nucleotide databases (GenBank, EMBL).

\section{PROTEIN EXPRESSION LIBRARIES}

For high-throughput screening, proteins are expressed on a clonal basis from automatically handled and arrayed cDNA expression libraries of different tissues of human and model organism origin $[5,6]$. For this purpose, the cDNA libraries are prepared in suitable expression vectors. So far, most cDNA libraries were made by oligo dT priming on the poly A tail of mRNAs. This technology is well established and has been used for creating gene catalogues [7]. It does also ensure that the 3' ends of cDNAs are included in the clones since those often constitute expressed sequence tags (ESTs) sequenced by tag sequencing initiatives [8]. There are two major disadvantages with this technique. First, 5' ends are often 


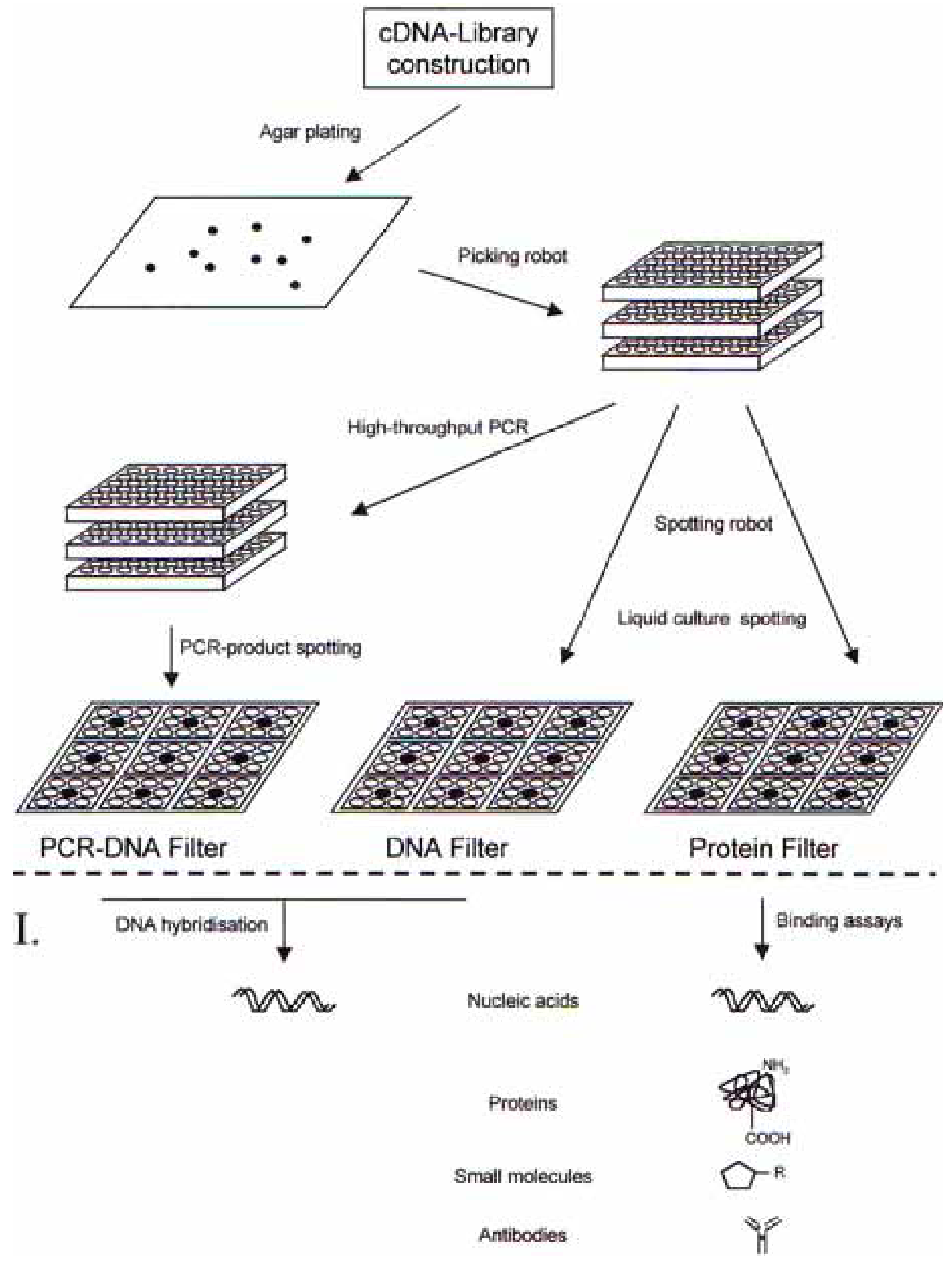

Fig. (2). (I.) Automated arraying of cDNA libraries into 384-well microtitre plates and onto filter membranes, creating DNA and Protein Filters [5]. (II.) Different options for molecular interaction screening of libraries on the respective high-density filters. 
missing from longer transcripts and second, 3' tags or reporter systems for expression are difficult to use, due to stop codons in the 3' untranslated regions (UTRs). An alternative to oligo dT priming is the use of random hexamers as primers for generating cDNA libraries. This technology enables to overcome problems with 3' UTRs, it allows the use of 3' tags and reporter systems for expression and results in a better representation of the 5' parts of genes in the cDNA libraries. In order to get full-length representation of genes in cDNA libraries, specialised technologies can be employed (e.g. CapFinder PCR cDNA Library Construction Kit, CLONTECH, Palo Alto, USA).

Initially, cDNA libraries are cloned into vectors suitable for protein expression in E. coli. These vectors encode an $\mathrm{N}$-terminal peptide tag (e.g. 6xHis) expressable as a fusion protein together with the cDNA-encoded protein. The tag enables easy detection and purification of the fusion protein and the application of high-throughput automation technology. In addition to vectors designed for cytoplasmic protein expression, leader sequences (signal peptides) can be incorporated for secretion into the periplasmic space/culture supernatant and further elements can be used for improving solubility (e.g. chaperones). To enable expression and interaction screening on as many proteins as possible, the following options are available for the production of protein expression libraries.

\section{CELLULAR OR SOLUBLE PROTEIN EXPRESSION}

cDNA is size-fractionated by gel filtration, and individual fractions are ligated into a bacterial expression vector, e.g., pQE-30NST (GenBank

\section{A method for high-throughput selection of binding partners}

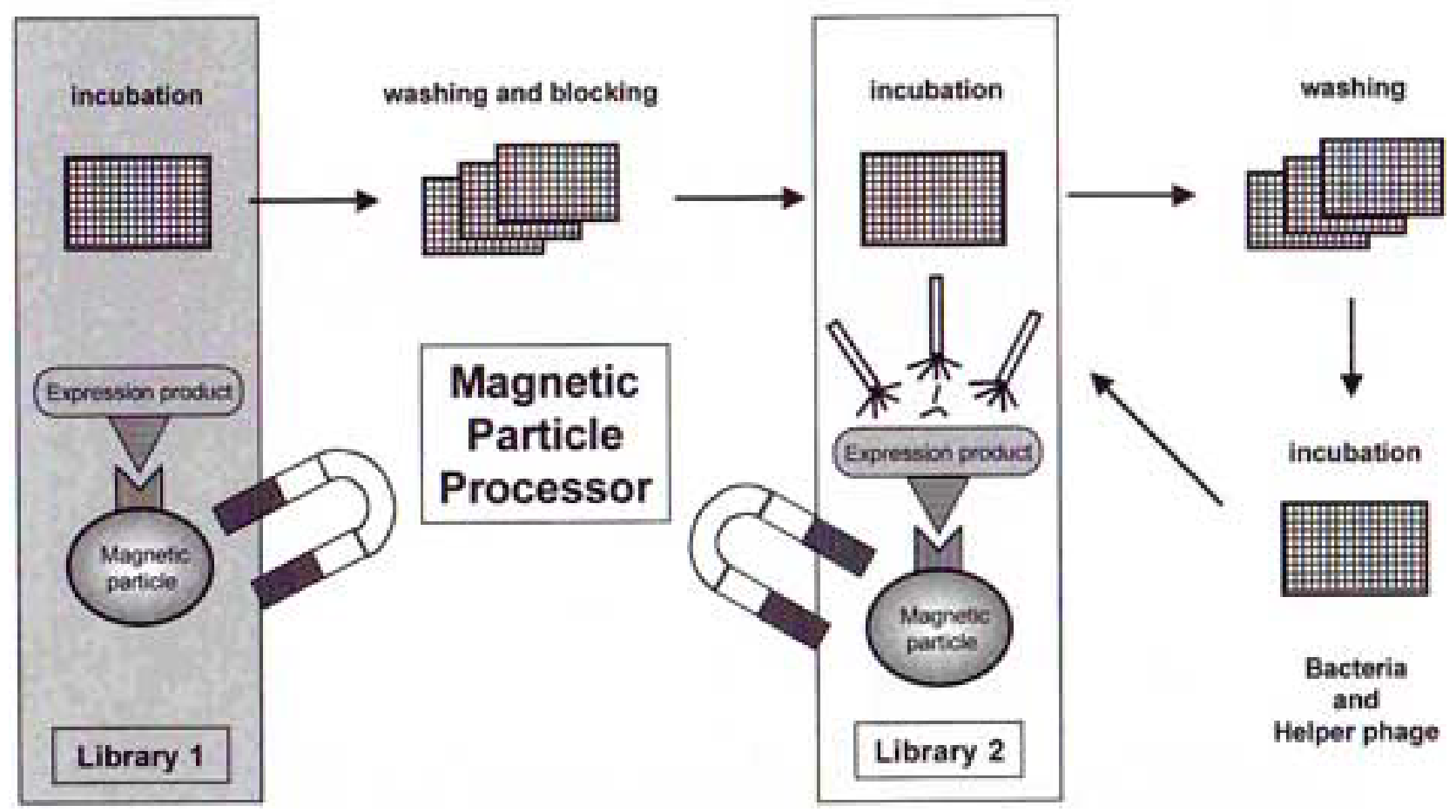

Fig. (3). High-throughput selection of binding partners. Magnetic particles are transferred between wells of microtitre plates using an automated magnetic particle processor. Molecules of the arrayed Library 1 (ligands) are tag-bound to magnetic particles that are washed, blocked and incubated with Library 2 (receptors), being a phage display library. After washing away background phage and incubation with bacteria and helper phage, an enriched and amplified Library 2 enters the next round of selection against the same Library 1 molecules for further enrichment. 
Accession no. AF074376), a modified Qiagen vector (Qiagen, Hilden, Germany), for IPTGinducible expression of $\mathrm{His}_{6}$-tagged fusion proteins. The ligation mixture is purified, and $E$. coli cells (e.g. strain SCS1, Stratagene, La Jolla, USA) are transformed by electroporation [5, 6]. Although the expression of recombinant proteins in $E$. coli is mostly the first choice for simplicity and yield, there are serious limitations. As E. coli is unable to make post-translational modifications like glycosylation, many human proteins are insoluble or misfolded and not expressed in a functional form. Likewise, membrane proteins are difficult to express in E. coli. Therefore, eukaryotic expression systems are used as alternatives.

\section{BACTERIAL PROTEIN EXPRESSION IN MICROTITREPLATES}

Bacterial colonies picked, replicated and grown in 384-well microtitre plates are usually transferred into 96-well plates and induced for protein expression by growth in inducer (e.g. IPTG)-containing media [6]. Cells are lysed by incubation in detergent-containing buffer solutions. Expressed proteins are purified from lysates by capture onto solid supports (e.g. magnetic beads) coated with a specific ligand (e.g. chelator) binding to the tag part of the fusion protein. Purified proteins can be eluted from the solid support and spotted onto PVDF filters using the spotting robot. Alternatively, captured proteins remain on the support for selection of interacting molecules from phage display libraries Fig. (3).

\section{BACTERIAL PROTEIN EXPRESSION ON PVDF FILTERS}

Bacterial colonies spotted onto PVDF filters (Protein Filters, Fig. (2) and grown overnight on NUNC agar plates are induced for protein expression by transfer of the filters onto IPTGcontaining plates [5]. Cells are lysed by incubating the filters in detergent-containing buffer solutions and processed according to established blotting technology (e.g. SDS-NaOH-Neutralisation-SSC). For detection of protein expression, the filters are washed, blocked with a suitable protein-containing buffer solution (e.g. 2\% milk powder), and incubated with a specific ligand or antibody binding to the fusion tag (e.g. 6xHis). Ligand/antibody binding is detected by an enzyme- labeled second ligand/antibody and either coloured or fluorescent substrate reaction.

\section{EUKARYOTIC EXPRESSION (YEAST, INSECT CELLS, MAMMALIAN CELLS)AND IN VITRO EXPRESSION BY COUPLED TRANSCRIPTION-TRANSLATION}

Alternatively, cDNA libraries can be cloned in vectors that allow protein expression in eukaryotic cells. Typically, that is either yeast (Pichia pastoris, Saccharomyces cerevisiae and Schizosaccharomyces pombe) providing the most advanced options, with vectors for intracellular and secretory expression in these organisms under development [9]), insect [10] or mammalian cells [11]. These approaches are essential for the expression of proteins that can not be properly expressed in E. coli. As another alternative for such gene products, in vitro expression by coupled transcription-translation systems (e.g. with internal biotin labeling) are used. These in vitro expression systems offer the additional advantage of expressing toxic proteins that would not be expressable in living cells.

\section{HIGH-THROUGHPUT PROTEIN IDENTI- FICATION}

\section{Protein-Chemical Techniques}

Protein species are identified according to their size by gel electrophoresis and/or mass spectrometry [6]. Purified proteins are eluted from solid supports (e.g. magnetic beads) and checked for size by gel electrophoresis at high throughput. Matrix-assisted laser desorption/ionisation timeof-flight mass spectrometry (MALDI-TOF-MS) is used to accurately identify sizes of proteins immobilised on solid supports. Additionally, peptide fragments can be generated by tryptic digestion, purified by liquid chromatography or capillary electrophoresis and their size can be determined by MALDI or electrospray mass spectrometry. The resulting fingerprints of peptide masses can be used for assigning proteins to known sequences using the MOWSE (Molecular Weight Search) database $[12,13]$ or similar databases.

\section{Interaction Techniques on Protein Filters}

High-density Protein Filters are produced by spotting onto PVDF filters either bacterial colonies 
or (purified) lysates of cells grown in liquid culture $[5,14]$. Such Protein Filters are used for systematic analyses of protein-protein interactions Fig. (2), e.g. screening of cDNA expression libraries for specific ligand-binding proteins [15] [16]. These protein arrays might also become a preferred tool for recombinant antibody library screening. Tomlinson and coworkers at the Medical Research Council, Cambridge, U.K. [17], have used Protein Filters to develop a system of 'naive' screening that could be applied to the highthroughput isolation of specific antibodies against many different targets in the human proteome.

\section{Phage Display Expression Libraries}

Complementary to automated (robotic) library handling, phage display is used for recombinant protein expression and the selection of interacting (binding) molecules. The main precondition for this selection is the physical link between an interacting molecule, (e.g. a protein) and the DNA sequence encoding it. This link between phenotype and genotype allows selective isolation and amplification of a particular phage encoding a desired gene product from pools of millions of phage [18]. The genome of a filamentous bacteriophage (e.g. fd) is used as a vector for cloning peptide or protein libraries, molecules are expressed as fusion proteins with a coat protein (e.g. protein III) and displayed on the phage surface.

\section{Random Peptide Phage Libraries}

Peptide libraries were the first libraries to be displayed on phage [19]. In the meantime, a wide variety of different peptide libraries were made, with different degrees of randomness and special means of recombination (for example see reference [20]). Peptide libraries are especially useful for mapping interacting parts of proteins (e.g. domains or epitopes). They are also a first step towards the production of small molecules that simulate protein actions.

\section{cDNA Expression Phage Libraries}

Although phage display has been used extensively for the selection of peptides and antibodies, it has its limitations when it comes to the expression of unknown sequences from cDNA libraries. As many of these sequences contain stop codons in their 3' untranslated regions, it is not recommended to directly fuse these sequences to the N-terminus of a phage coat protein. To overcome these problems, a cloning and expression system which allows the display of functional cDNA expression products on the surface of filamentous bacteriophage has been developed [21, 22]. This system exploits the high-affinity interaction of the Jun and Fos leucine zippers. Gene jun is expressed from a lacZ promoter as a fusion protein with the phage coat protein III. Using a second lacZ promoter of the phagemid, gene fos is co-expressed as an N-terminal fusion peptide with the cDNA library gene products, so that the resulting Fos-fusion proteins can become associated with the Jun-decorated phage particles. To avoid interphage exchange of fos-cDNA fusion products, cysteines were engineered at the $\mathrm{N}$ - and C-termini of each of the leucine zippers, providing a covalent link of the cDNA gene products to the genetic instructions required for their production. Dissociation between phage and cDNA gene products is readily achieved using reducing agents.

\section{Recombinant Antibody Phage Libraries}

Recombinant immunoglobulin gene libraries cloned in phage or phagemid vectors are an in vitro simulation of antibody repertoires and allow the production of antibodies without immunisation and without the use of animals [23]. Human antibodies against large numbers of different antigens, including human proteins, can be produced by phage selection of single-chain $\mathrm{Fv}$ (scFv, [24]) or Fab fragments [25]. Those antibodies should be particularly valuable as therapeutic agents since the patient's immune system will not recognise them as foreign. While the first monoclonal antibodies approved to treat cancer (e.g. Rituximab, Food and Drug Administration, U.S. Department of Health and Human Services, P97-39, Nov 26, 1997) still contain mouse sequences, the new reagents are completely human. Such libraries have for instance been built from individual immunoglobulin gene clones, sequenced and mapped in the laboratory of Greg Winter at the Medical Research Council's Laboratory of Molecular Biology, Cambridge, U.K. [26-29]. 
Besides antibodies, also enzymes, enzyme inhibitors, receptors, hormones, lymphokines and DNA-binding molecules have been target molecules displayed on filamentous phage. The wide range of possible applications clearly demonstrates the high potential of linking genotype and phenotype as a tool for the development of new molecules.

\section{Phage Display Selection of Interacting Molecules}

Phage surface display allows the selection of specific clones from large libraries, using the discriminative power of affinity purification. Selection is accomplished by interaction between the displayed gene product and a ligand immobilised on a solid phase. The selected phage are amplified by infection of E. coli cells which, after helper rescue, produce large numbers of new phage. Successive rounds of selection and amplification allow selective enrichment of phage, displaying gene products with affinity for a desired ligand. As a consequence of the physical linkage between genotype and phenotype, sequencing the DNA of the phage insert can readily elucidate the amino acid sequence of the displayed gene product. Automated (robot) technology enables high-throughput selection of two libraries against each other, hence creating interaction catalogues Fig. (1).

\section{Panning on Plastic Surfaces}

Panning of various molecules (e.g. proteins) on plastic surfaces is well established for the selection of binding molecular species (e.g. antibodies). While the first partner is either unspecifically adsorbed to the surface or specifically bound via another ligand, the second partner is bound to the first during incubation and eluted after washing away unspecific binders. This system is widely used for the selection of interacting molecules from phage display libraries. Target molecules are mainly immobilised on immunotubes or microtitre plate wells [30].

\section{Interaction in Solution}

For a closer simulation of in vivo situations, selection of interacting molecules can be done in solution. If the first partner (e.g. antigen) is labelled (e.g. biotinylated), molecules recognising this label (e.g. streptavidin) can be used to capture specifically binding molecules of the second partner (e.g. antibody) from a phage display library. Magnetic particles which, compared to immunotubes or microtitre plate wells, have the advantage of much higher binding capacities, have been the preferred solid phase for this kind of phage display selection [2, 31-37].

\section{Specific Tag-Binding of Ligands to Magnetic Particles}

Nonspecific adsorption of proteins to plastic surfaces leads to partial denaturation and destruction of epitopes. In contrast, tag-binding preserves native structures, ensures their proper orientation and enables direct loading of magnetic particles with ligands from protein mixtures such as crude extracts or cell lysates. This is particularly important for high-throughput selection technology, avoiding the purification of large numbers of different proteins. As most popular examples, $\mathrm{His}_{6}$-tagged proteins are bound to Ni-NTA Beads (Qiagen, Hilden, Germany), and biotin-tagged proteins are bound to Dynabeads M280 Streptavidin (Dynal, Oslo, Norway). The concentration of target molecules (ligands) on solid surfaces is a critical parameter for the selection of binding partner molecules (receptors). Optimal concentrations of protein ligands for loading of magnetic particles can be assessed in saturation ELISA experiments (Konthur et al., in preparation). For most proteins tested, concentrations of 5-10 $\mu \mathrm{M}$ purified ligand (e.g. 200-400 $\mu \mathrm{g} / \mathrm{ml}$ GAPDH) were found to cause saturation of $10 \mu \mathrm{l}(250 \mu \mathrm{g}) \mathrm{Ni}$-NTA Silica Beads or $20 \mu \mathrm{l}\left(1.34 \times 10^{7}\right.$ particles $)$ Dynabeads M-280 Streptavidin. These concentrations are in excess of saturating concentrations of other plastic surfaces (e.g. microtitre plates [38]) and confirm the high binding capacity of magnetic particles, reflecting their large surface area. While it is advisable to work with saturating concentrations if possible, some protein ligands can not be produced in sufficient amounts. In such cases, sub-saturating concentrations of protein ligands were used successfully, due to the high sensitivity of the magnetic particle technology. 


\section{Robot Selection}

Manual phage display selection is laborious, difficult to standardise in terms of precisely reproducible conditions and impossible to automate. Therefore, to enable selection in an automated way at high-throughput, we developed a technique for the selection of interacting molecules from molecular libraries by a combination of phage display and magnetic bead technology Fig. (3). Proteins expressed from arrayed cDNA libraries are bound to magnetic beads via a suitable molecular tag (e.g. $\mathrm{His}_{6}$ or biotin). Phage displaying specifically interacting molecules are fished out of a library by binding to their interaction partners attached to the beads. This selection involves a sequence of binding and washing steps and was adapted to high throughput using a magnetic particle processor. At the current state of development, the automated setup enables simultaneous selection of up to 48 samples and is microtitre plate-based. Target molecules are coupled to magnetic particles and can be handled as native ligands. Phage selection and amplification between selection rounds is done in microtitre plates. Binding activity is confirmed by magnetic particle ELISA in the same format.

\section{Advantages of an Automated Magnetic Particle Processor}

The use of an automated magnetic particle processor adds specifically to the distinct advantages of magnetic particle selection technology in terms of sensitivity, control and automation. First, numbers of magnetic particles can be scaled down compared to the manual technique, causing much less nonspecific background binding of phage. Second, the total

\section{Magnetic particle ELISA with polyclonal mixtures of phage from different rounds of selection}

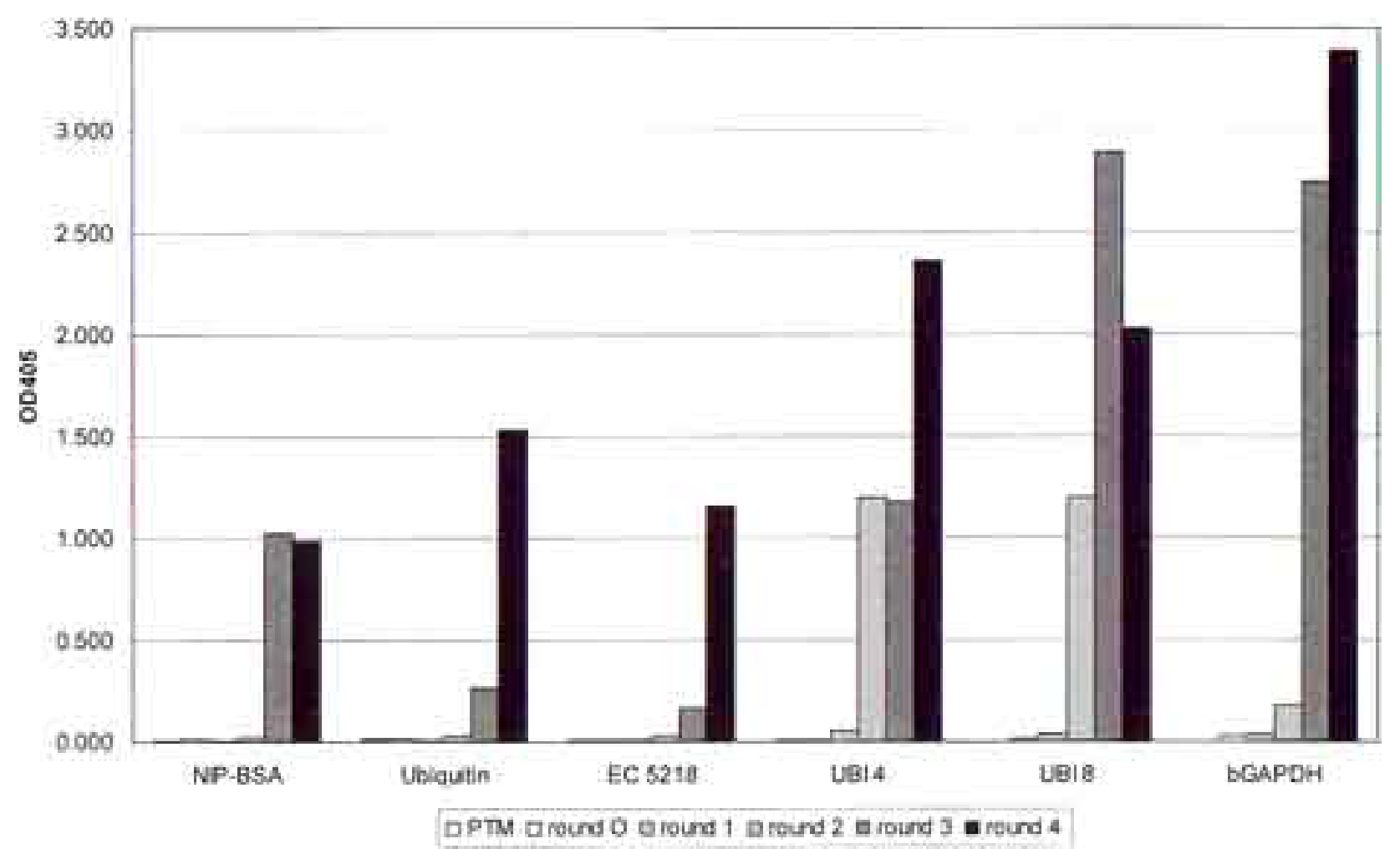

Fig. (4). Magnetic particle phage ELISA with polyclonal mixtures of phage, representing the unselected library (round 0) and the results of each round of selection (round 1-4), screened for binding partners to the respective ligands used in the selection (NIP-BSA, Ubiquitin, protein EC 5218 [6], UBI4, UBI8, bGAPDH); PTM as negative control. 
starting numbers of phage can also be scaled down, allowing for phage amplification in microtitre plates between selection rounds. Third, all washing and incubation conditions can be reproducibly customised. Most importantly, washing speeds are adjustable in order to cause different stringencies of selection and to enable the predictable selection of binders of different affinities. Fourth, high-throughput selection of binding partners and automation of the whole selection procedure becomes possible, as large numbers of library clones can be handled in parallel.

\section{High-Throughput Selection and Screening of Binding Partners}

Using this technology, we have screened phage display libraries of receptors and selected human $\mathrm{scFv}$ antibody fragments (Tomlinson, unpublished) against expression products of human cDNA libraries and various other ligands
(Konthur et al., in preparation). Phage titres were recorded after consecutive selection rounds to monitor the selection/amplification process (data not shown). Using the magnetic particle phage ELISA, polyclonal mixtures of phage, representing the unselected library and the results of each round of selection, were screened for binding partners to the respective ligand used in this selection Fig. (4). Positive mixtures were cloned, and single colonies were rescreened by magnetic particle phage ELISA for binding to the same ligand Fig. (5).

\section{Characterisation of Interacting Molecules}

A central criterion for the evaluation of molecular interactions is the binding affinity of partners to each other. There are several techniques available for measuring affinity, such as Fluorescence Quenching [39], Competition ELISA [40] and Surface Plasmon Resonance (BIAcore, [41] [42]). The new BIAcore 2000 and 3000 instruments (BIAcore, Uppsala, Sweden) lend

\section{2 anti-UBI 8 monoclonal phage from the 4 th round of selection}

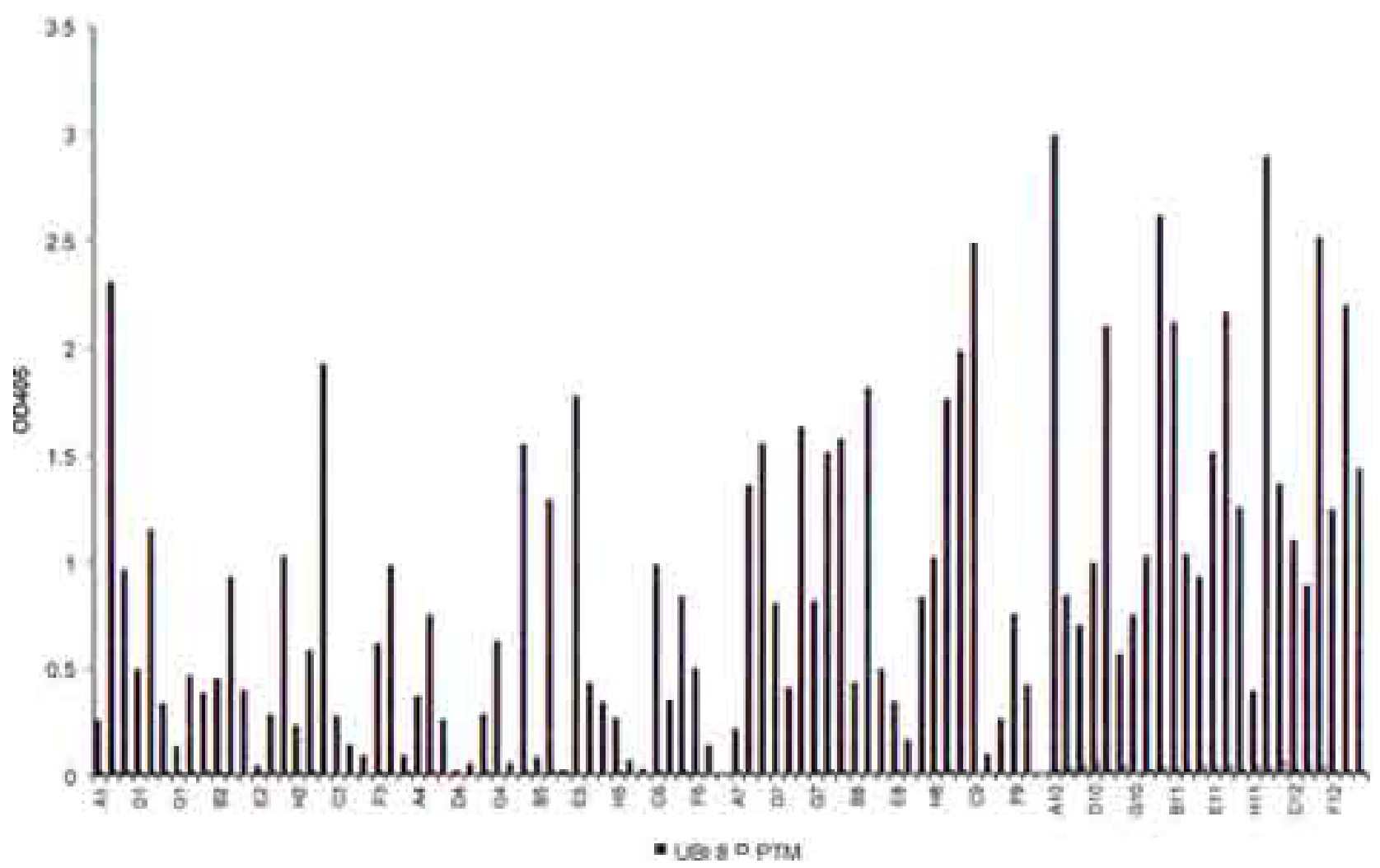

Fig. (5). Ninety-two monoclonal phage (anti-UBI8) from the 4th round of selection, rescreened by magnetic particle phage ELISA for binding to the same protein ligand (UBI8); PTM as negative control. 
themselves especially to the integration into automated genome technology for affinity measurements of interacting molecules at high throughput. In addition, Western blots and immunohistochemistry on cells and tissue sections are used to characterise the binding of antibodies and other selected receptor molecules to human proteins.

\section{CONCLUSION}

Molecular interactions are central to life, organising communication within and between cells. As this communication is highly complex, it is important to study interactions between individual components to get an idea of how the whole system works. For the interactive genomics concept discussed here, the analysis starts with binding studies between different molecules in vitro. High-density formats (e.g. microtitre plates and membrane filters) are ideally suited to automated interaction screening at high throughput. Using robot technology, large numbers of samples can be arranged in convenient formats and handled in parallel. Therefore, binding studies can be done in a very cost-effective way and can be used for pre-screening before in-depth analyses of molecular interactions are started. High-density protein arrays can be used to study proteinprotein, protein-nucleic acid and protein-small molecule interactions.

We have developed a high-throughput method for selection of binding partners from molecular libraries. Phage display technology enables the enrichment of specific binders, physically linked to the genetic information encoding them. Our method is based on the use of automated (robot) technology for efficient parallel handling of large numbers of clones. Library 1 (ligands) is tag-bound to magnetic particles, automatically handled by a magnetic particle processor, whereas library 2 (receptors) is a phage display library in liquid phase. Ligand production, magnetic particle loading, phage selection, phage amplification and magnetic particle ELISA for confirmation of binding activity is all done in microtitre plates. The whole procedure is automatable, from magnetic particle loading of ligands out of complex molecular mixtures to confirmed clones of receptors. At the present state of development, up to 48 samples can be handled simultaneously, and several runs of the magnetic particle processor can be performed per day. This technology has been successfully used to select human scFv antibody fragments that recognise specific expression products of a human cDNA library, indicating its general applicability for the selection of interacting molecules.

\section{ABBREVIATIONS}

$$
\begin{array}{ll}
\text { CCD } & =\text { Charge-coupled device } \\
\text { ELISA } & =\text { Enzyme-linked immunosorbent assay } \\
\text { EST } & =\text { Expressed sequence tag } \\
\text { GAPDH }= & \begin{array}{l}
\text { Glyceraldehyd-3-phosphate } \\
\text { dehydrogenase }
\end{array} \\
\text { IPTG } & \text { Isopropyl- } \beta \text {-D- } \\
& \text { thiogalactopyranoside } \\
\text { MALDI- }= & \text { Matrix-assisted laser desorption/ } \\
\text { TOF-MS } & \text { ionisation time-of-flight mass } \\
\text { PBS } & =\text { Phosphate-buffered saline } \\
\text { PCR }= & \text { Polymerase chain reaction } \\
\text { PTM }= & \text { PBS-Tween-milk powder } \\
\text { PVDF }= & \text { Polyvinylidene difluoride } \\
\text { ScFv }= & \text { Single-chain variable fragment } \\
\text { UBI }= & \text { Ubiquitin } \\
\text { UTR }= & \text { Untranslated region } \\
&
\end{array}
$$

\section{REFERENCES}

[1] Maier, E., Bancroft, D.R., Lehrach, H. In Automation technologies for genome characterization; Beugelsdijk, T.J., Ed., John Wiley \& Sons, Inc: 1997; pp. 65.

[2] Lehrach, H., Bancroft, D., Maier, E. Interdisciplinary Science Rev., 1997, 22, 37.

[3] Maier, E., Meier, E.S., Ahmadi, A.R., Curtis, J., Lehrach, H. J. Biotech., 1994, 35, 191.

[4] Meier, E.S., Lange, J., Gerst, H., Herwig, R., Schmitt, A., Freund, J., Elge, T., Mott, R., 
Herrmann, B., Lehrach, H. Nucleic Acids Res., 1998, 26,2216 .

[5] Büssow, K., Cahill, D., Nietfeld, W., Bancroft, D., Scherzinger, E., Lehrach, H., Walter, G. Nucleic Acids Res., 1998, 26, 5007.

[6] Büssow, K., Nordhoff, E., Lübbert, C., Lehrach, H., Walter, G. Genomics, 2000, 65, 1.

[7] Meier-Ewert, S., Maier, E., Ahmadi, A., Curtis, J., Lehrach, H. Nature, 1993, 361, 375.

[8] Adams, M.D., Kerlavage, A.R., Fleischmann, R.D., Fuldner, R.A., Bult, C.J., Lee, N.H., Kirkness, E.F., Weinstock, K.G., Gocayne, J.D., White, O., et, a.1. Nature, 1995, 377 supp., 3.

[9] Lueking, A., Holz, C., Gotthold, C., Lehrach, H., Cahill, D. Protein Expression and Purification, 2000, 20, 372 .

[10] McCarroll, L., King, L.A. Curr. Opin. Biotechnol., 1997, 8, 590 .

[11] Werner, R.G., Noe, W., Kopp, K., Schluter, M. Arzneimittelforschung, 1998, 48, 870 .

[12] Pappin, D.J.C., Hojrup, P., Bleasby, A.J. Curr. Biol., 1993, 3, 327.

[13] Clauser, K.R., Hall, S.C., Smith, D.M., Webb, J.W., Andrews, L.E., Tran, H.M., Epstein, L.B., Burlingame, A.L. Proc. Natl. Acad. Sci. USA, 1995, 92, 5072 .

[14] Lueking, A., Horn, M., Eickhoff, H., Büssow, K., Lehrach, H., Walter, G. Anal. Biochem., 1999, 270, 103.

[15] Sparks, A.B., Hoffman, N.G., Mcconnell, S.J., Fowlkes, D.M., Kay, B.K. Nat. Biotech., 1996, 14, 741.

[16] Walter, G., Büssow, K., Cahill, D., Lueking, A., Lehrach, H. Curr. Opin. Microbiol., 2000, 3, 298.

[17] Holt, L.J., Büssow, K., Walter, G., Tomlinson, I.M. Nucleic Acids Res., 2000, 28, E72.

[18] Kay, B.K., Winter, J., McCafferty, J. Phage Display of Peptides and Proteins. A Laboratory Manual, Academic Press Inc: San Diego, CA, 1996.

[19] Smith, G.P. Science, 1985, 228, 1315.

[20] Fisch, I., Kontermann, R.E., Finnern, R., Hartley, O., Solergonzalez, A.S., Griffiths, A.D., Winter, G. Proc. Natl. Acad. Sci. USA, 1996, 93, 7761.

[21] Crameri, R., Suter, M. Gene, 1993, 137, 69.

[22] Crameri, R., Blaser, K. Int. Arch. Allerg. Immunol., 1995, 107, 460 .
[23] Winter, G., Griffiths, A.D., Hawkins, R.E., Hoogenboom, H.R. Аnnu. Rev. Immunol., 1994, 12, 433.

[24] Nissim, A., Hoogenboom, H.R., Tomlinson, I.M., Flynn, G., Midgley, C., Lane, D., Winter, G. EMBO J., 1994, 13, 692.

[25] Griffiths, A.D., Williams, S.C., Hartley, O., Tomlinson, I.M., Waterhouse, P., Crosby, W.L., Kontermann, R., Jones, P.T., Low, N.M., Allison, T.J., Prospero, T., Hoogenboom, H.R., Nissim, A., Cox, J.P.L., Harrison, J.L., Zaccolo, M., Gherardi, E., Winter, G. EMBO J., 1994, 13, 3245.

[26] Tomlinson, I.M., Walter, G., Marks, J.D., Llewelyn, M.B., Winter, G. J. Mol. Biol., 1992, 227, 776 .

[27] Walter, G., Tomlinson, I.M., Cook, G.P., Winter, G., Rabbitts, T.H., Dear, P.H. Nucleic Acids Res., 1993, 21, 4524.

[28] Cook, G.P., Tomlinson, I.M., Walter, G., Riethman, H., Carter, N.P., Buluwela, L., Winter, G., Rabbitts, T.H. Nat. Genet., 1994, 7, 162.

[29] Tomlinson, I.M., Walter, G., Jones, P.T., Dear, P.H., Sonnhammer, E.L., Winter, G. J. Mol. Biol, 1996, 256, 813 .

[30] Harrison, J.L., Williams, S.C., Winter, G., Nissim, A. Methods Enzymol., 1996, 267, 83.

[31] Hawkins, R.E., Russell, S.J., Winter, G. J. Mol. Biol., 1992, 226, 889.

[32] Low, N.M., Holliger, P.H., Winter, G. J Mol Biol, 1996, 260, 359.

[33] Schier, R., Balint, R.F., Mccall, A., Apell, G., Larrick, J.W., Marks, J.D. Gene, 1996, 169, 147.

[34] Schier, R., Bye, J., Apell, G., Mccall, A., Adams, G.P., Malmqvist, M., Weiner, L.M., Marks, J.D. J. Mol. Biol, 1996, 255, 28.

[35] McConnell, S.J., Dinh, T., Le, M.H., Spinella, D.G. Biotechniques, 1999, 26, 208.

[36] McConnell, S.J., Dinh, T., Le, M.H., Brown, S.J., Becherer, K., Blumeyer, K., Kautzer, C., Axelrod, F., Spinella, D.G. Biol. Chem., 1998, 379, 1279.

[37] Kirkham, P.M., Neri, D., Winter, G. J. Mol. Biol, 1999, 285, 909.

[38] Kala, M., Bajaj, K., Sinha, S. Anal. Biochem., 1997, 254, 263.

[39] Eisen, H.N. Meth. Med. Research, 1964, 10, 115.

[40] Friguet, B., Chaffotte, A.F., Djavadi-Ohaniance, L., Goldberg, M.E. J. Immunol. Methods, 1985, 77, 305. 
[41] Malmqvist, M. Curr. Opin. Immunol., 1993, 5, 282.

[42] Hefta, L.J., Wu, A.M., Neumaier, M., Shively, J.E. In Antibody Engineering, A Practical Approach;
McCafferty, J., Hoogenboom, H.R., Chiswell, D.J., Ed., IRL Press: Oxford, 1996; pp. 119. 